\title{
Staff development for online delivery: A collaborative, team based action learning model
}

\author{
Allan Ellis and Renata Phelps \\ Southern Cross University
}

For academics to successfully make the transition to online teachers or learning facilitators, they must do more than develop new technical skills. Online development and delivery requires new pedagogical approaches, challenging previous practices with regards to assessment, group interaction and student/teacher dialogue. Furthermore, it necessitates attention to issues concerning academic work practices. Online delivery challenges traditional notions of academics working in isolation and instead brings together teams of people each with unique skills, into a course design and development team.

This paper describes the early phases of a systems change approach being implemented in the School of Social and Workplace Development at Southern Cross University. An ongoing collaborative action learning model is described as a vehicle for staff development and change management. This consisted of twice weekly team meetings and training sessions. These sessions represented a balance of outside expertise and experiences being brought into the group, and reflective and "idea sharing" sessions amongst the development team itself. A mixture of technological, pedagogical and managerial issues were covered and discussions were fully documented throughout the process.

Information on changing staff attitudes was collected via a series of semistructured interviews recorded at various stages over the course of unit development and early delivery stages, as well as staff completing weekly "reflection sheets" on their experiences. Enthusiasm, collaboration and a sense of ownership are identified as major factors driving the change process. Major barriers included difficulties of dividing time between varied commitments, the importance of timeliness of training components and the need to develop policy and guidelines "on the run". Further data collection such as time commitments from staff and skill requirements at each phase of development were used to develop guidelines and recommendations for further rounds of development and for budgetary planning. 


\section{Introduction}

Much online development has traditionally occurred by what could be considered to be "online mavericks" or "early adopters" — individuals keen to experiment with technology and who already had the technical skills to put their own units online. That many of the first online units were about computer subjects is not surprising. Yet increasingly, as online course delivery becomes more widespread and accessible, less technologically literate staff will need to become involved in both development and delivery of online units. Both these trends in development have, and are, presenting unique difficulties and require substantial staff development initiatives (as has been discussed by Ellis, O'Reilly and Debreceny 1998).

The aftermath of the "early adopters" has been discussed by Slay (1999), who also points to other difficulties surrounding staff development, such as the fact that "some academics have felt overwhelmed by learning a new technology and appear so constrained by increased demands on their time that they have not known how to follow institutional trends and moves toward online teaching."

For academics to successfully make the transition to become online teachers or learning facilitators, they must do more than develop new technological skills. Online development and delivery requires new pedagogical approaches, challenging previous practices with regards assessment, group interaction and student/teacher dialogue. These challenges are not by any means new. They are similar to the challenges which academics faced when making the transition from face to face modes of delivery to distance education. Just as distance education increased the visibility and accountability of teaching practices so too does online teaching and learning, a notion discussed most recently by McDonald and Postle (1999).

Online development also provides another predicament, challenging traditional notions of academics working in isolation and bringing together teams of people each with unique contributions of skills to be made to course design, development and delivery.

Online development also requires careful attention to academic work practices issues, perhaps in a way that previous teaching modes never have. These include ongoing maintenance and updating issues, students expectations of teaching staff (particularly with regards contact times) and student support issues, including technical issues. More then ever before, collaborative relationships must come to bear on the teaching process, and with these changes, added staff and policy development. 
There are vast differences between individually driven initiatives and the systems change required to move an entire school's staff toward online delivery. Academic organisations are faced with considerable challenges, not only in terms of training and staff development, but in regards philosophy and ideological beliefs, motivation, culture change, and challenges to staffing roles and structures. This paper describes some of these challenges in the context of the experiences of one School at Southern Cross University. It describes the issues involved in beginning this process of change and the model of collaborative team based action learning implemented, including issues encountered in this process.

\section{Challenging traditional teaching paradigms}

While many Universities claim to offer courses online there is a great variation in what they actually mean by an online course. Some are taking the approach of "web enhancing"1 their existing courses. Others are "web mounting" 2 existing course material. There is an existing body of literature discussing these approaches (for instance Boalch, 1996; Arnold, 1997).

Fewer, however are redeveloping their units to take full advantage of the pedagogical opportunities provided by the new technology, particularly in relation to a full degree program. The literature relating to instructional design for online development is new and emergent and draws heavily on case study analysis from early projects (illustrated through the work of Brown and Thompson, 1997; McDonald and Postle, 1999). As yet very little theory and generalisable research has emerged in the field.

It is not the intention of this paper to detail changes to pedagogical approaches in online environments. This is done effectively by authors such as Wild and Omari (1996). It is sufficient to say that the design demands between these various approaches varies considerably and that it is the latter more intensive process which is under discussion within this paper.

1 "Web enhanced" is defined here as adding e-mail or web-based based interactivity to either a web mounted course or a paper-based distance education course without significant redesign of teaching and learning strategies. In some universities, web enhancement occurs to face-to-face programs with the use a Web site to provide information about lecture times, assignment dates and so on.

2 "Web mounted" is defined here as converting text-based materials (usually distance education materials) to HTML or other format for web-based delivery, perhaps with the addition of a discussion forum, once again without significant redesign of teaching and learning strategies. 


\section{Action learning and team collaboration as professional development tools}

The role which action learning and action research can play in both professional development and organisational change has been well documented in the literature (Zuber-Skerritt, 1991; 1992; 1993; 1996; Limerick, Passfield and Cunnington 1994; Bourner, \& Flowers, 1999). Action research involves "team research by practitioners into their own practice, rather than by specialists on their behalf" (Zuber-Skerritt, 1991, p. 113).

Given that online teaching and learning approaches are so rapidly evolving there is unlikely to be a strong body of theory and research to inform online teaching and learning development for some time. This is not to say that the literature is not emerging at a rapid pace, but that it is always likely to be one step behind recent developments. For this reason, action learning and team based approachs to online development are valuable models.

Action learning entails a simple but effective cyclical structure, which involves participants in planning, acting, observing and reflecting. Collaboration is also a major tenet of action learning, with small teams or "sets" working together on tasks or problems.

The need for team approaches in online and flexible delivery has been discussed recently by McDonald and Postle, (1999). Considerations in the need for team based development include:

- involvement of individuals with technological skill specialisation

- input from Instructional Design specialists

- sharing experiences and design ideas between unit developers and delivers (given new teaching medium and relative lack of experience and literature regarding different approaches)

- involvement of other staff (such as casual or part time staff) who may be teaching in the unit

- the need for ongoing support of students, including input from technical support staff. 


\section{The "SaWD Online" project}

The SaWD Online project represents a major initiative by the Executive of Southern Cross University and a major undertaking by the School of Social and Workplace Development (SaWD) to develop its undergrad-uate programs of study for online delivery. The primary focus is on the online development of the Bachelor of Social Science (BSocSc) degree. The Project was funded by Vice Chancellor's Innovations and Development Grant funding.

The first phase of development of the BSocSc degree commenced Semester 2, 1998, with the first 5 units delivered in Semester 1, 1999. Additional units will then be progressively developed over a 2 year period (i.e. 19992000) as Phases 2-5.

In this paper we discuss Phase 1 of development, with six academic staff involved in the development of five online units. Numerous general staff within the School were also involved in the project, undertaking roles such as project management, research, desktop publishing, admin-istration and student support. Staff from other areas of the University (such as the Teaching and Learning Unit, Library and IT section) were also involved, as will be discussed later in this paper. The authors of this paper were involved in the project in the capacity of Academic Coordinator (Allan Ellis) and Project Manager (Renata Phelps). This paper will focus primarily on SaWD staff, rather than individuals from other areas of the University.

Early meetings in relation to the Project involved the majority of staff within the School, both general and academic. From these initial meetings arose much of the shared understanding about the values, motives, philosophical and ideological foundations upon which the project was founded. Although not all staff within the School continued with regular involvement in the first phase of development, all were aware of the activities of the core Project Team and continued to receive feedback at various staff meetings and participated in policy and work practice decisions arising from the first phase of development. Many staff members, both full time and part time, maintained a regular monitoring/observation of the progress of the project, knowing that they would, in the near future be developing units themselves. Dissemination of information was facilitated via a discussion list.

It should be noted that the SaWD Online Project ran concurrently with other online initiatives in the wider Southern Cross University environment, including an initiative by the School of Law to develop an online Associate Degree in Law (Paralegal Studies). However the 
approach taken by the School of SaWD described in this paper, provided a significantly different focus to development than that taken elsewhere. It is not the purpose of this paper to provide a comparative analysis between this and other approaches, but simply to say that this project did not occur in isolation.

\section{Philosophical and ideological foundings}

This project was in many respects philosophically and ideologically different from other online initiatives in that:

a. the focus was on development of a full online degree, necessitating involvement of all academic staff, not just the most technologically focused;

b. our definition of "online development" required full re-design of units, not just "web mounting" or "web enhancing" existing paper based external materials;

c. it represented more than simply technological enhancement of teaching but instead student focussed pedagogically sound redesign of teaching approach;

d. it entailed changing work practices for all staff within the School, both academic and general;

e. it involved a concerted attempt to address issues of policy development both within the School and within the University.

The School of SaWD has long demonstrated an innovative and responsive approach to its course development, being an early adopter of paper based distance education materials in the early 90s. The School sees the move to online delivery as an essential response to changes in Higher Education provision, both nationally and internationally. It is both a responsive development to cater to the needs and demands from its existing client group and an important means of reaching new markets.

Staff view the move to online delivery as part of their long held philosophy of flexible learning principles and responsiveness to the needs of individual learners and organisations. Rather than simply duplicating existing teaching and assessment practices, online development was seen as an opportunity for exploring new ways of teaching and learning using technology, including collaborative teaching and learning processes and new approaches to information literacy and resource access. Our approach was to combine the best features of internal study with the best features of 
external study and to supplement this with new and innovative teaching and learning approaches which online technologies now make possible. Teaching staff are challenging the way that they deliver content and are creating new opportunities for students to learn in collaborative and highly interactive ways.

Of course, the developments within the School cannot be considered in isolation, but are a result of institutional culture and policy initiatives. Early moves to develop online materials at Southern Cross University have been described by Ellis (1995a; 1995b) Debreceny, Ellis and Chua (1995), Ellis, Wildman and O'Reilly (1996) and Debreceny and Ellis (1996). The early terminology used to describe these initiatives was "networked learning" which involved a model that proposed core teaching and learning elements be delivered over computer networks. It did not rule out minor or supporting materials being delivered to some students via traditional face to face or paper based modes as appropriate. The increased power and sophistication of desktop technologies, available to both staff and students, has mean that totally computer based delivery is now feasible. "Online learning" in its pure form is at the extreme end of the networked learning continuum where only electronic resources are provided to the student and all student-student and staff-student interaction occurs over the network.

The staff of SaWD believe that if the development of a networked learning model for course delivery at Southern Cross is to be successful in the long term it must involve more than just moving current paper based teaching materials onto the Web and showing staff how to use a few "cookbook" approaches to online delivery. It must involve skilling the staff in the use of current desktop computer technology, sound pedagogical strategies for using the technology and manageable work practices. Staff must "own" the technology and feel comfortable about using it in their everyday workplace practices.

A major element of the SaWD Online Project was staff development as we believe that staff must "own" online materials, feel confident about working in this new environment and appreciate its strengths and weaknesses. It was not enough for staff to "hand over" responsibility for their unit development to someone else. A useful analogy provided by one member of the Project Team was that of a scaffolding built up with experts "but if that scaffolding is taken away the building still stands" (Staff Development Meeting, 14/7/98). It was also seen as crucial that staff be given the time release and the support to develop new workplace practices. 
Thus, two explicit goals of the project are to "develop innovative teaching, learning and assessment practices that exploit the strengths of networked technologies" and to "provide SaWD staff with the knowledge and skills to develop, deliver and update online units".

\section{A staged model for online staff development}

Ellis (in press) proposes a model that recognises the need for different types and level of support at the various stages of an individual staff member's journey from "just being interested" in online teaching to being recognised as a "expert" and someone who is independently updating their knowledge and skills. This four stage model, while discussed in detail elsewhere (Ellis, in press), is briefly described here, to present the context for the project which this paper describes.

\section{Stage 1}

This involves activities that aim to raise the interest, and increase motivation of, individual staff members to the possibility of becoming involved in online course development. This stage can involve a wide range of activities including:

a. assisting, if necessary, individual staff members to acquire appropriate hardware and software and perhaps dialup access infrastructure.

b. providing them with a bookmarked set of sites (resources, courses etc) in their discipline or interest area.

c. providing short seminars on current Online activities within the institution, and talks by visiting experts.

The development of a level of enthusiasm in Stage 1 is important and in the long term is well worth the investment.

\section{Stage 2}

This involves focused support for the staff members to undertake a clearly defined online project. This stage can be broken down into three steps:

a. Development - training in instructional design and issues of online pedagogy as well as technical training with appropriate software products and course management shells. 
b. Delivery - it is vital that developed materials are tested by real students so that implementation issues can be recognised and addressed.

c. Revision (and eventually and second round of delivery) This stage involves supporting staff to review and modify the material initially developed on the basis of the experience and feedback provided by testers and/or the first intake of students.

\section{Stage 3}

This involves further developing and extending the staff member's skills by challenging them to extend their work into more complex areas involving a higher level of technical knowledge and more complex staffstudent and student-student interactions. It might involve various forms of synchronous chat, perhaps video sessions, collaborative projects, peer assessment.

\section{Stage 4}

This involves acknowledging the staff member's new skills and expertise by having them mentor and train staff members at Stage 1 . This stage recognises that the newly trained, skilled staff are now a resource who can be used in future activities. It is also a means to consolidate their learning.

\section{Previous experience of participants}

Five of the six staff involved in the project had had some degree of experience or staff development in online teaching and learning in the past. Many had commenced an in house course which had been run by Southern Cross' Technology in Teaching and Learning Unit in the previous year, although only one of them had completed this course due to time and priority constraints3.

3 When asked to reflect on the strengths and weaknesses of this online course, and the reasons why they did not complete the course, staff predominantly indicated that they did not have an immediate use for the knowledge they were gaining (i.e. the learning was not timely as they were not at that point developing online units). 
Three of the academic developers had been involved with teaching "web mounted4" and "web enhanced5" units at the postgraduate level6. All were aware of the limitations of these approaches, knowing that there "has to be something in it for the students". All were strongly committed to producing "something more" from this project: "I want to be involved in at least one really crash hot unit." One lecturer had experimented with using synchronous communications amongst his internal student group for several years previously. It was interesting for us to reflect in one of our early meetings on the experiences we had had as students in higher education. Of a group of 9 participants at this meeting our experiences as students in different delivery modes can be summarised as follows:

\begin{tabular}{|l|c|}
\hline Mode of delivery & $\begin{array}{c}\text { No. of participants } \\
\text { with experience }\end{array}$ \\
\hline Full time on campus & 7 \\
\hline Part time on campus & 4 \\
\hline External part time off campus & 9 \\
\hline External full time off campus & 3 \\
\hline Internal & 6 \\
\hline Distance & 4 \\
\hline Online & 1 \\
\hline
\end{tabular}

At least one staff member had thus been involved in studying online, but aside from that we recognised that we were really treading new ground that despite all our experiences, this was still very new and innovative for us. Everyone in the Team saw this as an exciting learning experience.

4 "Web Mounted" is defined here as converting text-based external materials to HTML for web-based delivery without significant redesign of teaching and learning strategies.

5 "Web Enhanced" is defined here as adding e-mail or web-based based interactivity to either a web mounted course or a paper-based distance education course without significant redesign of teaching and learning strategies.

6 Throughout 1996 and 1997 the School of Social and Workplace Development (SaWD) at Southern Cross University began to develop its postgraduate program for online delivery. In these early days of experimentation with online teaching and learning there was a dearth of documented experience in online delivery - others were certainly involved in these initiatives, usually individuals rather than full Schools or Faculties. 
Thus the project can really be seen as falling within Stage 2 of Ellis' (in press) proposed model for online staff development. The staff involved already had progressed through Stage 1 and had a significant level of enthusiasm.

\section{The collaborative action learning model}

Each of the five units under development was allocated a small development team, including at least 2, sometimes 3 or 4 academic staff and an Instructional Designer, drawn from the Teaching and Learning Unit of Southern Cross. These small development teams formed part of a larger development group which included Project Manager, Research Assistant, Desktop Publishers other administrative assistants, and IT staff. Brought into this process were other individuals in roles such as graphic designers, library staff, student administration and so on. The level of involvement of the latter of these roles varied, as did their participation in the action learning processes.

Throughout Semester 2, 1998, staff were involved in two weekly staff development workshops of two hours duration - a total of four hours of staff development each week. The focuses of these workshops varied considerable but can broadly be considered as falling into 4 categories:

1. Pedagogical

Viewing examples of online units - discussing how various strategies might be adapted to the units being developed.

Discussing innovative assessment approaches.

Collaborative blueprint development.

Sharing literature.

2. Technical

Discussions with IT staff regarding networks, servers, IT Web publishing policies.

Examination of available technologies, such as video, audio, HTML Editors (several sessions) - discussing how various strategies might be adapted to the units being developed.

Training in use of specific technologies such as sound file production, HTML editors and course management shell (Learning Space).

3. Administrative

Project Management including resource allocation, timeline management.

Copyright issues.

Development of School policies for instance containing/minimising workload. 
4. Team building

Sharing Team members' previous experience and ideas.

Collaborative blueprint development.

Mutual assistance with technology/pedagogy.

The staff development workshops were opportunities for staff to learn together, to challenge each others' designs and to share resources, ideas and frustrations. Each smaller unit development team also met separately to develop blueprints and to do the actual designing and developing.

\section{Data collection}

Data was collected during phase one of the project through three main mechanisms:

1. Pre and post development interviews

2. Documentation of staff development opportunities

3. Regular (weekly) personal reflections of participants

\section{Pre and post development interviews}

All academic staff involved in developing units were interviewed at two stages: at the beginning of phase one of the project (i.e. before any project activities occurred) and at the end of phase one of develop (before they began teaching their unit). These interviews were conducted in a collaborative context - not as a "researcher and subject" but as a process of producing a communal record for all the project team's benefit and all staff were enthusiastic about the value in documenting the processes. The discussion questions served as a guide only.

In the first round of interviews, staff were asked to reflect on:

- Why they wanted to be involved in the project (if in fact they did)

- Where they envisaged the project taking them personally

- What involvement they had had in online learning up till then

- Whether they had any initial ideas about the design of their unit

- What misgivings they had about the project.

In the second round of interviews, staff were asked to reflect on:

- the most useful and least useful aspects of the online staff development sessions

- the course materials they produced in the first phase of development

- whether they feel confident in teaching using these materials?

- their main concerns about teaching online this semester? 
- their thoughts regarding the project processes

\section{Documentation of staff development opportunities}

Documentation was made of the majority of staff development opportunities. This involved either note taking during the staff development workshops and sessions or tape recording of discussions with subsequent note taking from the recording. This documentation also served as a means of communication to individuals who were unable to attend any session and also to other staff not involved in the weekly meetings.

\section{Regular personal reflections of participants}

Action learning models generally involve participants keeping a reflective learning journal as a means of recording their experiences and personal development and learning as a result of involvement in the project. Being mindful of the time constraints of staff and the added demands being placed on their time through involvement in the project a slightly different approach was taken to recording reflections. Staff were asked to spend the last 5-10 minutes of the second staff development workshop each week responding to some reflective questions and recording their experiences and time expenditure for that week.

Unit developers were also encouraged to keep a personal journal. While several staff, including the Project Manager, began using this process, it was difficult to maintain a regularity in this practice, and the official weekly jottings thus became a valuable source of data.

\section{Time allocation and breakdown}

Academic staff were asked to record on a weekly basis the time they committed to the online project and to indicate how this time was allocated. This recording was considered vital in informing future phases of the project and in planning and budgeting for academic staff release time. An indication of how academic staff spent their time on the project is provided in the following figure: 


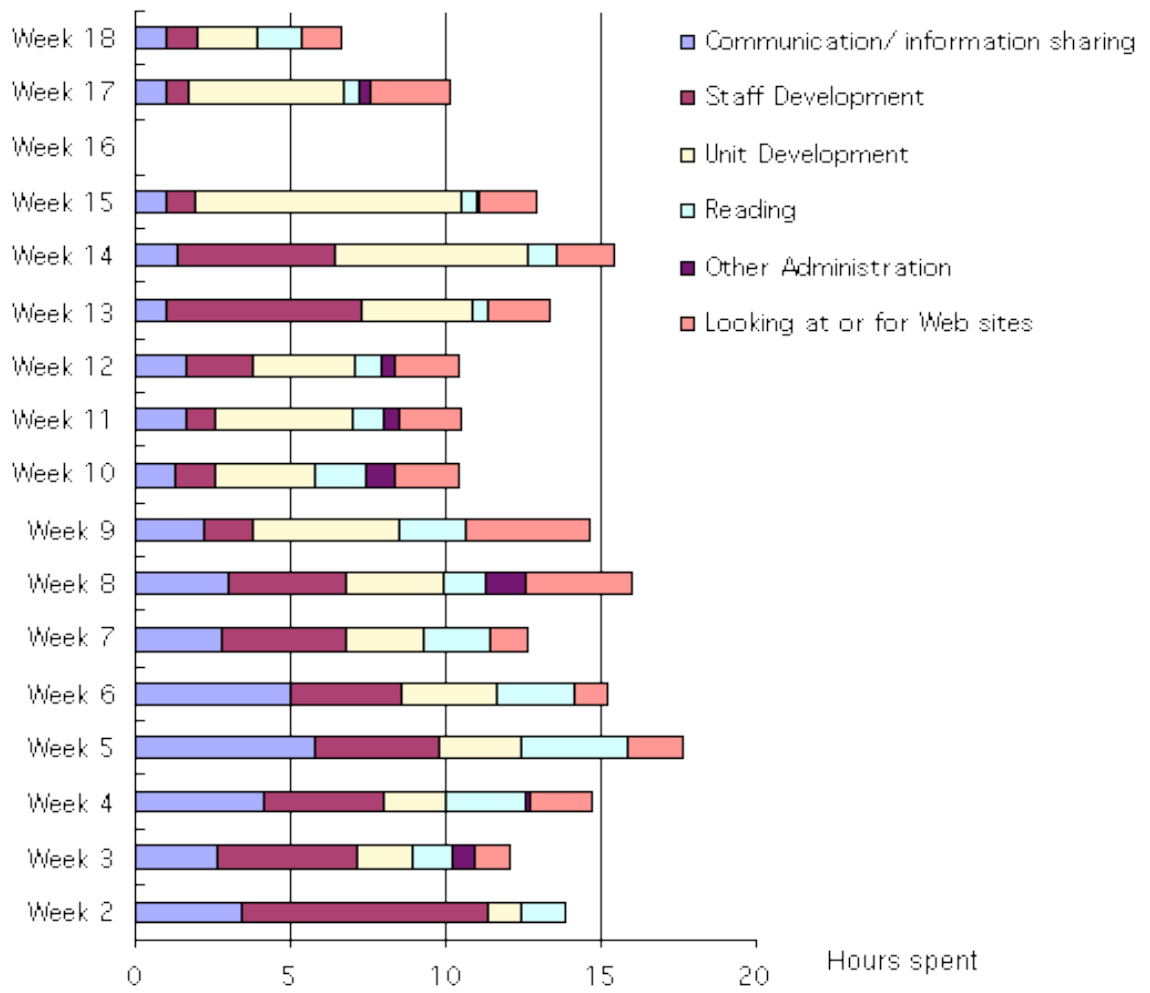

Figure 1: Average allocation of staff time for staff and unit development (Weeks 2-18)

\section{Capitalising on enthusiasm}

Perhaps the biggest advantage we had in Phase 1 of the project was the level of commitment of staff. All staff were extremely enthusiastic about involvement in the project. They saw the project as vital for a number of reasons including: 
- improvement in teaching and learning, including individualisation of programs

- international marketability of courses

- opportunity to target niche markets.

It is important not to overlook the importance of this enthusiasm. Staff were eager to get going early, and were at times frustrated by other areas of the University delaying progress, particularly while policy decisions were made. Enthusiasm was maintained through the team based collaboration model, as is illustrated below.

When asked what misgivings staff initially had about involvement with the project, the following were cited:

- Time involved in development and maintenance

- The possibility that time limitations may mean we had to cut corners and would end up doing something conventional - yet keen that we design from scratch and consider pedagogical effectiveness

- Fear students may have of technology

- Lack of wider university infrastructure

All of there initial misgivings did in fact become realities, some of which are detailed later in this paper.

\section{From enthusiastic beginner to peak performer}

It must be emphasised that the academic staff of the School of SaWD, given their disciplinary background in adult learning and training and development were extremely cognisant of their own learning processes. Most of them were experienced in reflective learning and critical self reflection and this added to the quality of the data obtained through this process. One of the unit developers shared her reflections with the group one week using a model of situational learning developed by Zigarnin, Blanchard and Zigamin (1985):

$$
\begin{gathered}
\text { Enthusiastic Beginner — Disillusioned learner - Variable Contributor } \\
\text { — Peak Performer }
\end{gathered}
$$

The lecturer paralleled her own learning to that which will be expected of the online student, indicating that until the previous day she had felt like an "enthusiastic beginner" but given technical difficulties in the previous 24 hours she was now a "disillusioned learner". Understanding and sharing her experiences gave her the confidence to move through this phase. 


\section{Collaboration into action: Beyond "official" staff development}

The added benefits of the collaborative team based approach to staff development were highlighted away from the official staff development sessions. A particularly illustrative example of this was in the unit developers' determination and enthusiasm to produce sound files. This is best illustrated through the reflections of one of the authors as Project Manager.

Quite early in the project we purchased some simple shareware software for producing and editing sound files. While all the academic staff had quite workable computer skills they were certainly not technologically advanced users. None of the unit developers had been involved with producing sound files previously. As most readers may be aware, Friday afternoons are not a time when academic staff are renowned for being locatable in their offices! However throughout the progress of the project this timeslot, following the morning's staff development sessions, became a Mecca for online activity. This particular Friday, the Project Manager chanced past the offices to find a babble of activity - four of the academic staff had helped each other to install and learn to use the software (including some complex problem solving), and within an hour or so were producing welcome messages for their students. It was some weeks before the "official" staff development session on sound production could be scheduled and already these staff were confident users.

\section{Emerging issues, learnings and policy implications}

A number of key issues emerged throughout Phase 1 of the project in relation to school policies and pedagogical design. Some of these evoked lively and ongoing debate and were not able to be immediately resolved. These issues are presented here as significant learnings from the project:

- The question of whether to continue to use any print based material (given issues of overseas delivery), including the issue of whether units should have text books.

- Issue of rolling enrolments - non-concurrent study patters of students create difficulties for group interaction. While many benefits were recognised in maintaining flexibility for students in study patterns there were also recognised benefits of group interaction.

- Issues of minimum levels of involvement by academic staff (i.e. how much does the academic have to do?) 
- Recommendations regarding nominal release allocations for staff involved in development (Note that the calculations on staff loading vary considerably between universities and schools so the release recommended is not generalisable.

- Work practice issues, both with regards development and delivery, including explication of expectations of staff regarding students and students regarding staff. In the case of this project School policy was developed to ensure a certain minimum number of weeks (3) when students did not expect staff to interact intensively with them online.

- The benefits of integrating teaching and research.

- The value of cross fertilisation of ideas and experiences. In particular, the group developed a sense of cohesiveness which was extremely supportive as development progressed. Sharing of blueprints was seen as beneficial for most staff involved, and from a project management perspective ensured that the pressure to keep to deadlines was maintained.

- Following first phase of development, staff were more aware of the time consuming nature of online delivery; It "takes as much time as you can give it" was one staff member's comment. A number of staff felt on reflection that an intense development "retreat" would be an effective forum for development with all relevant staff removing themselves from their day to day routines and being able to devote solid time to design and development. This suggestion is valid as it would also create a good opportunity for team collaboration and ready access to all individuals in the various roles.

- The important role of the Instructional (or Educational) Designer in fostering staff development and promoting innovative design developments, particularly through cross fertilisation. This concept is not by any means new, and has been described in the early distance education literature (Kember and Mezger 1990).

- The most difficult aspect of staff development processes is in managing the timeliness of learning opportunities. There is a fine balance between exposing staff to technological possibilities and overwhelming them with technology which they do not immediately use.

- The importance of staff being involved in policy decisions, but of these decisions being made in a timely and efficient manner so as not to delay development progress. 
The team based action learning model utilised for Phase 1 of this project provided a unique perspective on staff development for online teaching and learning and provided insights on issues which may not have otherwise occurred. The strongest value, however, in this approach was the mutual support that staff gained, knowing that others were facing, and together solving, the challenges of this new teaching environment.

\section{References}

Arnold, M. (1997). Using the web to augment teaching and learning. Paper presented at ASCILITE97. http:/ / www.curtin.edu.au/ conference / ASCILITE97 / papers / Arnold / Arnold.html

Boalch, G. (1996). WWW as an educational support medium: An Australian case study. Paper presented at AusWeb96.

http:/ / www.scu.edu.au/sponsored/ausweb/ausweb96/educn/boalch/paper.html

Bourner, T. and Flowers, S. (1999). Teaching and learning methods in higher education: A glimpse of the future.

http: / / www.bbk.ac.uk/Learning / ASD/bourne.htm

Brown, A. and Thompson, H. (1997). Course design for the www - keeping online students onside. Paper presented at ASCILITE97.

http:/ / www.curtin.edu.au/conference/ ASCILITE97/ papers/Brown/Brown.html

Burnett, D. (1999). Pedagogical alternatives for web based instruction. Paper presented at AusWeb99. http:/ / ausweb.scu.edu.au/aw99/ papers/burnett/

Debreceny, R. and Ellis, A. (1996). Developing and implementing information technology in teaching and learning: A critical success factors perspective. Paper presented to 13th Annual Conference of the Australian Society for Computers in Learning in Tertiary Education, University of South Australia, eds A. Christie, P. James \& B. Vaughan, Faculty of Health and Biomedical Sciences, University of South Australia, pp. 149-161.

Ellis, A., O'Reilly, M. and Debreceny, R. (1998). Staff development responses to the demand for online teaching and learning. Paper presented at ASCILITE98. http: / / cedir.uow.edu.au/ ASCILITE98/asc98-pdf/ellis0005.pdf

Ellis, A. (in press). Instructional support for web based courseware development. Journal of Education and Information Technologies.

Gilbert, C. (1996). Teaching and learning on the web at Queensland University of Technology. Paper presented at AusWeb96.

http:/ / www.scu.edu.au/sponsored/ausweb/ausweb96/educn/gilbert/paper.html

Kember, D. and Mezger, R. (1990). The instructional designer as a staff developer: A course team approach consistent with the concerns based adoption model. Distance Education, 11(1), 50-70. 
Limerick, D., Passfield, R. and Cunnington, B. (1994). Transformational change: Towards an action learning organisation. The Learning Organization, 1(2), 29-39.

McDonald, J. and Postle, G. (1999). Teaching online: Challenge to a reinterpretation of traditional instructional models. http: / / ausweb.scu.edu.au/aw99/ papers / mcdonald/ paper.htm

Slay, J. (1999). Creating an online learning environment: Issues in academic staff development. Paper presented at AusWeb99. http: / / ausweb.scu.edu.au/aw99/ papers/ slay2 / paper.html

Wild, M. and Omari, A. (1996). Developing educational content for the Web: Issues and ideas. Paper presented at AusWeb96.

http://www.scu.edu.au/sponsored/ausweb/ausweb96/educn/wild/paper.html

Zigarnin, P., Blanchard, K. and Zigamin, D. (1985). SLII: A situational Approach to Managing People: Module III: Diagnosis. Blanchard Training and Development, Escondido, CA.

Zuber-Skerritt, O. (1991). Action research as a model of professional development. In O. Zuber-Skerritt (Ed), Action Research for Change and Development. Avebury, Aldershot, pp.112-135.

Zuber-Skerritt, O. (Ed) (1992). Professional Development in Higher Education: Theoretical Framework for Action Research. Kogan Page, London.

Zuber-Skerritt, O. (1993). Improving learning and teaching through action learning and action research. Higher Education Research and Development, 12(1), 45-58.

Zuber-Skerritt, O. (1996). Emancipatory action research for organisational change and management development. In O. Zuber-Skerritt (Ed), New Directions in Action Research. Falmer Press, London, pp. 83-104.

Allan Ellis, School of Social and Workplace Development

Renata Phelps, School of Education

Southern Cross University

Email: aellis@scu.edu.au 